\title{
China's Food Security Evaluation Based on Factor Analysis
}

\author{
Jie Zou, Shiqin Guo \\ School of Economics and Management, Southwest Jiaotong University, Chengdu, China \\ Email: zoujie765@outlook.com
}

Received 28 May 2015; accepted 26 June 2015; published 29 June 2015

Copyright (C) 2015 by authors and Scientific Research Publishing Inc.

This work is licensed under the Creative Commons Attribution International License (CC BY). http://creativecommons.org/licenses/by/4.0/

c) (i) Open Access

\begin{abstract}
China's food security has been a hot issue of social concern. Based on existing studies, this paper chose 12 factors to establish comprehensive evaluation system of good security, including the arable land area per capital, the fluctuation rate of grain yield, the grain price rising rate, the degree of agricultural mechanization, etc. Comprehensive evaluation of China's food security over the years by factor analysis shows that China's food security is in a tense balance state, the sources of which are the supportability factor slowdown and the score of stability factor decrease. Base on the analysis, we proposed to strengthen financial support to agriculture, improve the land protection mechanism, and improve the utilization rate of grain and other countermeasures to ensure China's food security in the future.
\end{abstract}

\section{Keywords}

Food Security, Analysis System, Factor Analysis, Structural Contradiction

\section{Introduction}

Food security is related to national social stability and economic development; it's the foundation of national security. Ensuring food security was always one of the basic national polices in China. Since in 2004 Chinese government changed the food subsidy mechanism from indirect subsidy to direct subsidy, China has obtained ten years' continuous increase of grain production. However, series of unstable elements are hidden behind: reduction of cultivated land resources, continuous rise of international food prices, shortage of water resources, and rigid growth in food demand, which are severely affecting China's food security. Therefore, researching food security problem contributes to grasping the development trends of China's food security situation, and has practical significance to make national policies, dissolve risk and guarantee food security.

Food security was always a hot issue among theorists. Many scholars have studied on it, and there are differ- 
ent cognitions. Brown (1995) [1] thought that in the process of industrialization, accompanied by increased demand for food and cultivated land reduction, China would inevitably import large amounts of grain from the international market where there was not enough grain supply. Therefore, China would be confronted with serious grain shortage. Ma et al. (2005) [2] thought that no food security problem existed in China, but grain shortage would appear in a long-term development view. Yu et al. (2003) [3] and Fu (2001) [4] studied China's food security problem from point of view of the resource constraints. The results showed that subject to a decline in the quantity and quality of cultivated land, water resources shortage and other factors, China's food security situation was hard in the future. Chen (2005) [5] and Yang (2010) [6] predicted China's future food production and demand using prediction model. The results showed that China would face food gap in long time. However, some of scholars held the opposite view. Mao (2004) [7] believed that the overall situation of world grain was oversupply. As long as the market mechanism was brought into full play, there would be no food security problem. He et al. (2004) [8] and others have made empirical analysis on China's macroscopic food security from the points of view of grain production, grain supply and international comparison. The results show that China's food security is on a high-level. Wu et al. (2010) [9] and other scholars used EPIC model and IFPS IM space model to evaluate China's food security with factors of per capita grain occupancy and GDP. The conclusion was that there was no food security problem in China. Ma et al. (2001) [10] and Liu (2004) [11] have made empirical research on China's food security situation by constructing a comprehensive evaluation system. The conclusion is that the food security situation in China is good. In response to the different views above, this paper proposes and explores the following questions: how are China's food security situation and the development trend, what's the major factor influencing China's food security, and how to ensure the food security in the future.

\section{Construction of Food Security Evaluation Index System}

In 1996, FAO defined food security in the world grain leadership conference as that all people can access to sufficient, safe, and nutritious food at any time. Thus, the connotation of food security mainly includes plenty of grain supply, grain acquisition ability and nutritious grain, covering the macroscopic food security in national level and microscopic food security in family and individual levels. Food security relates to food production link, circulation link and consumption links.'

Building an objective, reasonable, and scientific index system is the premise for quantitative analysis and objective evaluation of China's food security. According to the connotation of food security, and based on the related researches of Liu (2004) [11], NBS (2005) [12] and other scholars, and on the basis of factor measurability, data availability, measure comprehensiveness and other principles, this paper selected 12 indexes covering grain production, circulation and consumption link to construct food security evaluation system, including the arable land area per capita, the ratio of grain sown area to crops sown area, the degree of agricultural mechanization, the grain gap per capita, the fluctuation rate of grain yield, per unit area yield of grain, agricultural labor force, inflation rate of grain price, per capita occupancy of grain, Engel's Coefficient of city and countryside.

\subsection{Grain Production Index}

1) Arable land area per capita $\left(I_{1}\right)$.

The arable land area per capita is a macroscopic index to reflect food security, because it is the foundation of grain production. Under a certain technical condition, the upper limit of grain yield is determined by the arable land area per capita. Therefore, guaranteeing certain amount of arable land is the premise of food security. With the development of China's industrialization and urbanization, arable land area per capita continuous decline, the contradictions between people and land are more and more sharp; cultivated land resources have become resource constraints restricting China's food security.

2) Grain gap per capita $\left(I_{2}\right)$.

The grain gap per capita is the most direct index to judge food security level; this index reflects whether the increasing speed of grain yield can meet the increasing speed of grain consumption. In 2012, our grain yield per capita was less than $437 \mathrm{~kg}$, while the grain consumption per capita was close to $500 \mathrm{~kg}$; the grain gap per capita was up to $12 \%$. In pace with economic development and improvement of consumption level, the transfer of grain consumption structure is accelerating, which will enlarge the grain gap per capita in China.

3) Agricultural labor force $\left(I_{3}\right)$. 
Agricultural production in China is still in a traditional stage, the transfer of agricultural labor to non-agricultural industries have profound effects on China's food security, embodying in two aspects: First, the continuous decline of agricultural labor force will cause a decline in China's grain production; Second, in the transfer process of agricultural labor to non-agricultural industries, their role also change from the food producers to food consumers, this change increase the gap between grain supply and demand (Fan, 2005) [13].

4) Fluctuation rate of grain yield $\left(I_{4}\right)$.

The country's fluctuation rate of grain yield has direct impact on stability of the per capita share of grain, thus affect the balance of grain supply and demand, and national food security. Valdes variation coefficient is used to measure the fluctuation rate of China's grain output (Liu, 2004) [14]:

$$
E_{t}=\beta_{1} \text { factor }_{1 t}+\beta_{2} \text { factor }_{2 t}+\beta_{3} \text { factor }_{3 t}
$$

$G_{t}$ means grain yield, $\bar{G}_{t}$ means grain trend yield, calculated from regression analysis of grain yields of five consecutive years.

5) Ratio of grain sown area to crop sown area $\left(I_{5}\right)$.

The ratio of grain sown area to crop sown area reflects farmer's initiative to plant grain; a bigger ratio means a higher wish of farmer to plant grain and a higher food security level.

6) Degree of agricultural mechanization $\left(I_{6}\right)$.

In this paper, we use the ratio of total power of agricultural machinery to grain planting area in China to reflect the degree of agricultural mechanization. In the process of urbanization, with the decline of agricultural labor population, development of mechanized grain production is inevitably required.

7) Per unit area yield of grain $\left(I_{7}\right)$.

Increasing grain production capacity is the fundament to guarantee food security; the basic indicator of grain production capacity is the total grain yield that depends on the sown area and per unit area yield of grain. The raod to substantially increase arable land to increase grain production is not in conformity with the basic national condition of arable land resources which is "one more and three less". Therefore, increasing per unit area yield of grain plays a vital role to ensure China's food security in the future. So in this paper, we take the per unit area yield of grain as an indicator of food security in China.

\subsection{Grain Circulation Index}

The template is used to format your paper and style the text. All margins, column widths, line spaces, and text fonts are prescribed; please do not alter them. You may note peculiarities. For example, the head margin in this template measures proportionately more than is customary. This measurement and others are deliberate, using specifications that anticipate your paper as one part of the entire journals, and not as an independent document. Please do not revise any of the current designations.

1) Grain trade dependency $\left(I_{8}\right)$.

Grain production in China does not only undertake market function like other production industries, but also undertakes a lot of "political" function (Huang, 2000) [15]; this feature determines that our food security problem must be solved independently. In addition, China's grain demand exceeded $50 \%$ of the global grain trade in 2011, means that all the world's exchangeable grain cannot feed China. Therefore, grain trade dependency $\left(I_{8}\right)$ is one of the important indices for evaluation of Food security in China, calculated as follows:

$$
R=(I-O) / D \times 100 \%
$$

$R$ means grain trade dependency, $I$ means grain import quantity, $O$ means grain export quantity, $D$ means total grain demand.

2) Inflation rate of grain price $\left(I_{9}\right)$.

On the one hand, grain price limits the consumer's ability to access grain through economic measures, it is a index to measure food security level in circulation; on the other hand, grain price is the direct reflection of the structure of grain supply and demand. Therefore, the inflation rate of grain price $\left(I_{9}\right)$ is an important indicator to measure food security.

\subsection{Grain Consumption Index}

1) Per capita occupancy of grain $\left(I_{10}\right)$.

The per capita occupancy of grain is a microcosmic index to reflect food security, and has direct impact on 
consumer's grain consumption level $(\mathrm{Hu}, 2000)$ [16]. One person requires at least $249 \mathrm{~kg}$ of grain to maintain minimum survival. If less than this standard, individual survival cannot be guaranteed, which would lead to a nationwide famine. Therefore, this paper takes the per capita occupancy of grain as index $I_{10}$.

2) Engel's Coefficient $\left(I_{11}, I_{12}\right)$.

In grain consumption link, consumer's payment ability is an important factor to measure food security level (Du, 2013) [17]. Grain consumption is closely related to food consumption, the close relationship of them is reflected in two aspects: first, consuming grain as food directly; second, indirect consumption that transfer grain to meat, egg, milk and other foods. The FAO divided food consumption into five levels according to the bigness of Engel's Coefficient, $0-0.29$ belongs to the richest level, $0.30-0.39$ belongs to the rich level, $0.40-0.49$ belongs to the well-off level, $0.50-0.59$ belongs to warm and feed level, and 0.60 - 1 belongs to poor level. Although consumption structure differences exist between different counties and districts, the Engel's Coefficient provides us a perspective to judge consumer's consumption level and payment ability from economical point of view. This paper takes city Engel's Coefficient and countryside Engel's Coefficient as index $I_{11}$ and $I_{12}$ (shown in Table 1).

\section{Empirical Analysis of Food Security in China}

\subsection{Data Source}

1) The arable land area per capita, fluctuation rate of grain yield, degree of agricultural mechanization and other indexes mainly come from statistical yearbooks. 2) The grain import and export data of year 1978-1984 comes from the book "Who Will Feed Us" of Mr. Xiangzhi Kong; the grain trade dependency data are mainly from "Chinese Agriculture Development Report" 2002 and 2012; the data of year 2013 is calculated from the national statistical bulletin. 3) The Engel's Coefficients in city and countryside from 1978-2012 are from the "China Civil Affairs' Statistical Yearbook" over the years (the data of 1979 is missing, calculated by method of linear interpolation). Among the 12 indexes affecting food security, index $I_{1}, I_{3}, I_{5}, I_{6}, I_{7}$ and $I_{10}$ are positive index, a bigger numerical value of which represents a higher level of food security; index $I_{2}, I_{4}, I_{8}, I_{9}, I_{11}$ and $I_{12}$ are reverse index, a higher numerical value of which represents a lower level of food security. In order to compare and analyze the indexes owning different dimensions and directions, this paper takes min-max standardization method to do normalizing processing of each index; the specific formula is as follows:

Table 1. Index evaluation system of food security.

\begin{tabular}{|c|c|c|c|}
\hline Primary index & Secondary index & Unit & Code \\
\hline \multirow{7}{*}{ Grain production link } & Arable land area per capita & hectare & $I_{1}$ \\
\hline & Grain gap per capita & $\mathrm{kg}$ & $I_{2}$ \\
\hline & Agricultural labor force & 10000 & $I_{3}$ \\
\hline & Fluctuation rate of grain yield & $\%$ & $I_{4}$ \\
\hline & Ratio of grain sown area to crop sown area & $\%$ & $I_{5}$ \\
\hline & Degree of agricultural mechanization & $\mathrm{kW}$ & $I_{6}$ \\
\hline & Per unit area yield of grain & $\mathrm{kg}$ & $I_{7}$ \\
\hline \multirow[b]{2}{*}{ Grain circulation link } & Grain trade dependency & $\%$ & $I_{8}$ \\
\hline & Inflation rate of grain price & $\%$ & $I_{9}$ \\
\hline \multirow{3}{*}{ Grain consumption link } & Per capita occupancy of grain & $\mathrm{kg}$ & $I_{10}$ \\
\hline & City Engel's Coefficient & $\%$ & $I_{11}$ \\
\hline & Countryside Engel's Coefficient & $\%$ & $I_{12}$ \\
\hline
\end{tabular}


Formula of positive index:

$$
I^{*}=\frac{I_{i}-\operatorname{MinI}}{\operatorname{MaxI}-\operatorname{MinI}}
$$

Formula of reverse index:

$$
I^{*}=\frac{\operatorname{Max} I-I_{i}}{\operatorname{Max} I-\operatorname{Min} I}
$$

Through above formulas, the standardized numerical matrix of each food security index from year 1978-2013 is calculated out.

\subsection{Factor Analysis}

The weight of each evaluation index is a significant element for final evaluation results of China food security. There are subjective method and objective method to determine the weight of each index. As the indexes are numerous, and one evaluation index is closely related to each other, there are overlapping among them. Subjective weight determining method can't be used to evaluate food security because it cannot reflect the inner link, which will affect the accuracy and objectivity of evaluation results (Fu, 2011) [18]. In order to eliminate the interference caused by the correlation between the evaluation indexes, and objectively reflect food security situation in China, this paper uses factor analysis method.

Factor analysis is one kind of statistical method to extract few representative public factors from numerous variables, explain and analyze the relationship between variables, by means of dimension reduction. Correlation and public factor must exist between the original variables; it is the precondition of factor analysis. Therefore, we need to test the correlation between variables before factor analysis.

\subsubsection{Statistical Test}

There are Bartlett Test of Sphericity and KMO (Kaiser-Meyer-Olkin) Test to judge whether the variables are suitable for factor analysis. Test results are illustrated in Table 2. The value of KMO test is 0.627 . Value range of KMO test given by Kaiser (1974) [19] is $(0,1)$; the value is more close to 1 , it is more suitable to do factor analysis; when $\mathrm{KMO}>0.6$, factor analysis feasible. The $\mathrm{P}$ value of Bartlett test is 0.000 , passing the test.

\subsubsection{Factor Selecting and Naming}

We select factor from variables by using main ingredient analysis method to do factor analysis, and combining the principle that the cumulative contribution rate of main ingredient variance exceeding $85 \%$ and the characteristic root is greater than 1 . Table 3 shows that the characteristic roots of first three factors are all bigger than 1 , the cumulative contribution rates of variance is $86.03 \%$, which means the three main factors could well replace the original 12 indexes to describe and explain food security problem in China. The three main factors abstracted are named as factor 1 , factor 2, and factor 3 .

In order to better observe load relation between the public factors and variables, the maximum variance method is used to do orthogonal rotation for the factor-loading matrix. Changing the contribution rate of each factor while the cumulative variance contribution rate remains unchanged to make the factor loading coefficient values differentiating to 0 or 1 .

Illustrated in Table 4, the arable land area per capita, city Engel's Coefficient, countryside Engel's Coefficient, ratio of grain sown area to crop sown area, degree of agricultural mechanization, per unit area yield of grain and other variables mainly represent grain supply ability and access ability, undertake safeguarding function in food security, and have higher loading coefficients in factor 1 . Therefore, the first main factor is named as safeguarding factor. The factor 2 has higher loading coefficients in the grain trade dependency, grain gap per capita, agricultural labor force and other variables that influence the stability of food security, thus is named as stability factor. At last, the factor 3 has higher loading coefficients in the inflation rate of grain price, fluctuation rate of grain yield and other variables, thus is named as fluctuation factor.

\subsubsection{Food Security Score}

The variance contribution rate of safeguarding factor, stability factor and fluctuation factor divide by cumulative variance contribution rate of all the factors, and then we can get the weights of three factors. Using factor weight 
Table 2. KMO and bartlett's test.

\begin{tabular}{lcc}
\hline \multicolumn{2}{c}{ Kaiser-Meyer-Olkin (KMO) measure of sampling adequacy } & 0.627 \\
\hline & Approx chi-square & 850.791 \\
Bartlett's test of sphericity & $\mathrm{df}$ & 66 \\
& Sig. & 0.000 \\
\hline
\end{tabular}

Table 3. Characteristic root and variance contribution rate.

\begin{tabular}{ccccccc}
\hline Component & \multicolumn{3}{c}{ Initial eigenvalue } & \multicolumn{3}{c}{ Rotation sums of squared loadings } \\
\hline & Total & \% variance & Cumulative \% & Total & \% variance & Cumulative \% \\
\hline 1 & 6.569 & 54.739 & 54.739 & 6.080 & 50.664 & 50.664 \\
2 & 2.378 & 19.816 & 74.554 & 2.844 & 23.698 & 74.362 \\
3 & 1.378 & 11.482 & 86.037 & 1.401 & 11.675 & 86.037 \\
\hline
\end{tabular}

Table 4. Rotated factor loading coefficient.

\begin{tabular}{|c|c|c|c|}
\hline Index & Factor $_{1}$ & Factor $_{2}$ & Factor $_{3}$ \\
\hline Arable land area per capita & -0.986 & -0.106 & 0.045 \\
\hline Grain gap per capita & -0.407 & 0.879 & 0.086 \\
\hline Agricultural labor force & 0.152 & 0.926 & -0.043 \\
\hline Fluctuation rate of grain yield & -0.067 & -0.285 & -0.772 \\
\hline Ratio of grain sown area to crop sown area & -0.961 & 0.007 & -0.101 \\
\hline Degree of agricultural mechanization & 0.926 & -0.340 & -0.069 \\
\hline Per unit area yield of grain & 0.972 & -0.088 & -0.050 \\
\hline Grain trade dependency & -0.054 & -0.192 & 0.849 \\
\hline Inflation rate of grain price & -0.359 & 0.894 & 0.066 \\
\hline Per capita occupancy of grain & 0.590 & -0.182 & -0.150 \\
\hline City Engel's Coefficient & 0.940 & -0.140 & 0.155 \\
\hline Countryside Engel's Coefficient & 0.908 & -0.330 & 0.062 \\
\hline
\end{tabular}

to multiply the score of the each factor, and then add them together, we can get the comprehensive score of China's food security level from 1978 to 2012. The weight of each factor is explained by their variance contribution. The formula is as follow:

$$
E_{t}=\beta_{1} \text { factor }_{1 t}+\beta_{2} \text { factor }_{2 t}+\beta_{3} \text { factor }_{3 t}
$$

E means comprehensive score of food security, $t$ means year $(\mathrm{t}=1978 \ldots 2012), \beta$ means weight. After calculation, the food security score of each factor and the comprehensive score of food security in China over the past years are illustrated in Table 5.

\subsection{Empirical Result Analysis}

The food security score of each factor and the comprehensive score of food security in China over the past years can be calculated out with the above model, as shown in Table 6. The empirical result shows that China's food security situation can be divided into two phases; the turning point is year 2002. The first phase is from 1978 to 2002, when the scores of food security present an upward trend. The score in 1978 is 0.28 , but it is 0.85 in 2002 ; 
Table 5. Factor analysis result of food security.

\begin{tabular}{|c|c|c|c|c|c|}
\hline Year & Factor1 score & Factor2 score & Factor3 score & Total & Normalization \\
\hline 1978 & -1.0290 & -0.1376 & 0.1809 & -0.9856 & 0.2935 \\
\hline 1979 & -0.9151 & -0.1819 & 0.0276 & -1.0695 & 0.2674 \\
\hline 1980 & -0.8675 & -0.1839 & 0.1072 & -0.9442 & 0.3064 \\
\hline 1981 & -0.8086 & -0.2092 & -0.0240 & -1.0418 & 0.2760 \\
\hline 1982 & -0.6831 & -0.1790 & 0.0143 & -0.8478 & 0.3364 \\
\hline 1983 & -0.6032 & -0.1335 & 0.0195 & -0.7172 & 0.3771 \\
\hline 1984 & -0.4828 & -0.0467 & 0.0896 & -0.4398 & 0.4636 \\
\hline 1985 & -0.4075 & 0.0783 & -0.0762 & -0.4054 & 0.4743 \\
\hline 1986 & -0.3925 & 0.0448 & -0.0889 & -0.4366 & 0.4646 \\
\hline 1987 & -0.3551 & -0.0565 & -0.0612 & -0.4729 & 0.4533 \\
\hline 1988 & -0.2828 & -0.0041 & -0.0799 & -0.3669 & 0.4863 \\
\hline 1989 & -0.2860 & 0.0090 & -0.1530 & -0.4301 & 0.4666 \\
\hline 1990 & -0.1535 & 0.1613 & 0.0796 & 0.0874 & 0.6278 \\
\hline 1991 & -0.1182 & 0.2340 & -0.0614 & 0.0543 & 0.6175 \\
\hline 1992 & -0.0342 & 0.3153 & -0.1517 & 0.1294 & 0.6409 \\
\hline 1993 & 0.0186 & 0.3691 & -0.1335 & 0.2542 & 0.6798 \\
\hline 1994 & 0.0159 & 0.3419 & -0.3217 & 0.0361 & 0.6118 \\
\hline 1995 & 0.0508 & 0.0894 & -0.1938 & -0.0536 & 0.5839 \\
\hline 1996 & 0.0961 & 0.1277 & 0.0880 & 0.3117 & 0.6977 \\
\hline 1997 & 0.0842 & 0.1778 & 0.1187 & 0.3807 & 0.7192 \\
\hline 1998 & 0.1920 & 0.2167 & 0.1429 & 0.5515 & 0.7724 \\
\hline 1999 & 0.2399 & 0.1989 & 0.0964 & 0.5352 & 0.7673 \\
\hline 2000 & 0.2844 & 0.1952 & 0.1061 & 0.5857 & 0.7831 \\
\hline 2001 & 0.3735 & 0.1753 & 0.0985 & 0.6473 & 0.8023 \\
\hline 2002 & 0.4576 & 0.2571 & 0.1176 & 0.8323 & 0.8599 \\
\hline 2003 & 0.5292 & 0.3069 & 0.2375 & 1.0736 & 0.8314 \\
\hline 2004 & 0.5499 & 0.0702 & -0.0538 & 0.5663 & 0.7770 \\
\hline 2005 & 0.5140 & -0.0199 & 0.0579 & 0.5520 & 0.7726 \\
\hline 2006 & 0.5186 & -0.0964 & 0.0311 & 0.4533 & 0.7418 \\
\hline 2007 & 0.5216 & -0.0897 & 0.0099 & 0.4418 & 0.7382 \\
\hline 2008 & 0.5474 & -0.2427 & -0.0806 & 0.2241 & 0.6704 \\
\hline 2009 & 0.5318 & -0.3285 & -0.0483 & 0.1549 & 0.6489 \\
\hline 2010 & 0.5766 & -0.4468 & -0.0888 & 0.0410 & 0.6134 \\
\hline 2011 & 0.6418 & -0.4352 & -0.0431 & 0.1635 & 0.6515 \\
\hline 2012 & 0.6752 & -0.5770 & 0.0367 & 0.1350 & 0.6426 \\
\hline Max & 0.6752 & 0.3691 & 0.2375 & 1.2819 & 1.0000 \\
\hline Min & -1.0290 & -0.5770 & -0.3217 & -1.9277 & 0.0000 \\
\hline
\end{tabular}


Table 6. Index component of factor.

\begin{tabular}{ccc}
\hline Code & Factors name & Secondary index \\
\hline & Arable land area per capita (I1) \\
& & Ratio of grain sown area to crop sown area (I5) \\
Factor1 & Degree of agricultural mechanization (I6) \\
& Safeguard factor & Per unit area yield of grain (I7) \\
& & City Engel's Coefficient (I11) \\
& & Countryside Engel's Coefficient (I12) \\
Factor2 & Stability factor & Grain gap per capita (I2) \\
& & Agricultural labor force (I3) \\
& & Grain trade dependency (I9) \\
Factor2 & Fluctuation factor & Grain trade dependency (I8)
\end{tabular}

the average annual growth rate is up to $4.5 \%$, and even more higher in years 1995 to 2002 . The second phase is from 2002 to 2012, in these ten years, the scores of food security in China represent a downward trend, except 2011.

In order to explore the reason why the scores change, and find the key elements that restrict China's food security, we made further analysis of the factors influencing food security. Table 3 shows that the first main ingredient, the safeguarding factor, has a largest variance contribution rate, the second factor and third factor decrease accordingly, thus we can make preliminary judgment that the safeguarding factor has a largest impact on improving food security level, the stability factor has a relative large impact, and the fluctuation factor has a small impact. The score of each factor over the years can further explain the determinants affecting food security. Figure 1 shows that the food security situation represents an upward trend when the safeguarding factor score stay in rapid raising phase, which means China's food security situation largely depends on growth rate of the safeguarding factor score. The scores of stability factor have a large fluctuation before 2002, and have almost the same change trend with the food security situation, a decline trend, which means the stability factor is restricting food security level. The score of fluctuation factor maintains a stable trend; the factor score weight is low, generally remaining at around $10 \%$, showing the fluctuation factor has a small impact on food security.

\section{Countermeasures and Suggestions}

This paper selected twelve indexes to build comprehensive evaluation system of food security, and used factor analysis method to evaluate the change trend of food security situation from 1978 to 2012, based on these indexes. Results show that: 1) China's food security is in short balance state, the score of which is between 0.7 and 0.6 in recent years and declines continuously, illustrating that the food security situation is not optimistic. 2) The degree of food security in China has been declining continuously, caused by decline of the score increasing speed of the safeguarding factor and score of stability factor. The source lies in two aspects. Firstly, with the development of social economy and the improvement of people's living standards, grain consumption structure changes, and the demand for grain increases significantly; secondly, restricted by reducing of cultivated land resources, descending of farmer's planting enthusiasm, and the lower agricultural mechanization degree and other elements, increasing speed of grain production slows down. Specifically speaking, the annual increasing rate of grain yield per capita was only $3.7 \%$ from 2002 to 2012, while the increasing rate of grain demand per capita was up to $5.4 \%$ at the same time, which was 1.45 times of the former. The main problem to secure China's food security is to solve the structural contradiction between grain production and demand. 


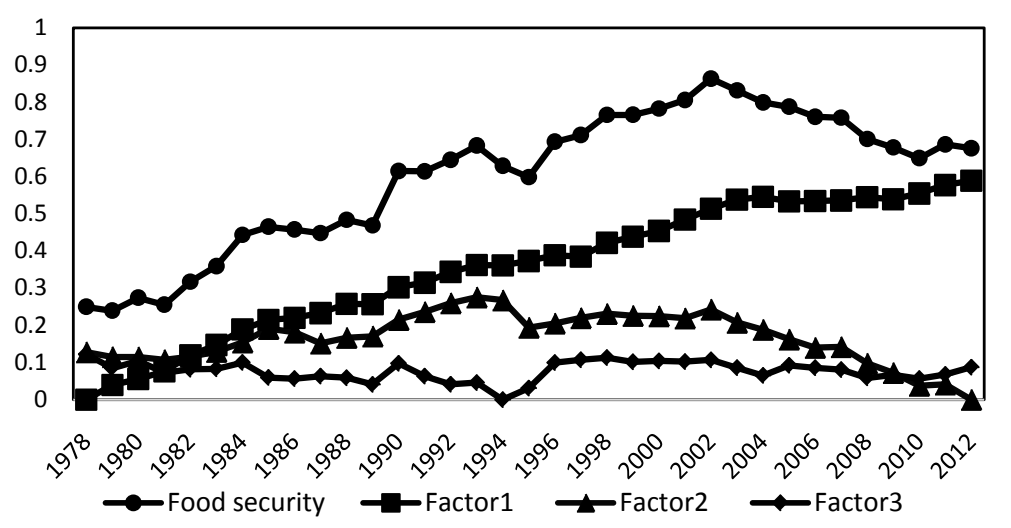

Figure 1. The variability in food security and each factor score. The data are standardized by the min-max normalization.

In order to eliminate the structural contradiction between grain production and demand, and secure China's food security, this paper proposed the following policy suggestions:

Firstly, it is necessary to increase financial supporting strength to agriculture, improving grain production ability. The fragility and quasi-public goods properties of grain industry determine that the improvement of grain production ability needs the increasing of financial supporting. In total, it is improving the share of agriculture supporting financial expenditure in total financial expenditure to promote the development of grain industry. On the structure of agriculture financial expenditure, it is necessary to increase finance to the basic agricultural construction, improve agricultural production conditions, and improve the efficiency of grain production. It is also vital to strengthen financial investment in agricultural science and technology, and promote the development of agricultural science and technology to realize the modernization of grain production. Continuously, it is necessary to strengthen the grain subsidies, increase the income of grain farmers and improve their enthusiasm to expand grain crops planting area and increase grain production effectively.

Secondly, we need to establish long-term effective mechanism to protect cultivated land, and reduce the constraints of cultivated land resource on food security. In terms of total cultivated land, we need to insist on the red line of 1.8 billion mu of arable land, and put an end to occupation of cultivated land, developing and reforming land to improve the utilization of land resources and increase arable land area effectively, in terms of cultivated land quality, strictly implementing the "high standard basic farmland construction specification". It is vital to reform land, improve the land quality and increase the proportion of high quality cultivated land.

Thirdly, under the perspective of grain consumption, we need to improve the utilization rate of grain and reduce the increasing rate in grain demand, to ease the structural contradictions of China's food security. In grain production and processing link, for example, we can put stress on supporting grain second processing and finishing processing enterprises and improve the conversion rate from grain into meat, eggs and milk. In the grain circulation link, we can establish modern grain purchase and storage system and transportation system, and reduce the loss of grain in circulation. In grain consumption link, advocate healthy and green food consumption idea, set up consumption consciousness of "love grain, treasure grain and save grain", and change the unreasonable consumption idea that pursuit of "bright, white and fine". To ensure China's food security, we not only need to open up the source, but also need to regulate the flow.

\section{References}

[1] Brown, L.R. (1995) Who Will Feed China? Wake-Up Call for a Small Planet. WW Norton \& Company.

[2] Ma, X.H., Lan, H.T. and Huang, H.Q. (2005) International Experience of Industry Nurturing Agriculture and Influencing on Choice of Agricultural Policy in China. Management World, 21, 55-63.

[3] Yu, Z.G. and Hu, X.P. (2003) Research on the Relation of Food Security and Cultivated Land's Quantity and Quality in China. Geography and Territorial Research, 19, 45-49. http://dx.doi.org/10.3969/j.issn.1672-0504.2003.03.013

[4] Fu, Z.Q., Cai, Y.L. and Yong, Y.X. (2001) Research on the Relationship of Cultivated Land Change and Food Security in China. Journal of Natural Resources, 16, 313-319. http://dx.doi.org/10.3321/j.issn:1000-3037.2001.04.003

[5] Chen, Y.F. (2005) Supply and Demand of Grain in China: A Projection. Problem of Agricultural Economy, 4, 8-14. 
http://dx.doi.org/10.3969\%2fj.issn.1000-6389.2005.04.002

[6] Yang, X.L. and Zhang, S.J. (2010) The Present Situation of China Food Security and the Countermeasure of Solving the Question. Economic Reviews, 25, 46-49.

[7] Mao, Y.S. (2004) On Food Security in China Again. Journal of Shanghai University of Finance and Economics, 6, 3-6. http://dx.doi.org/10.3969\%2fj.issn.1009-0150.2004.04.001

[8] He, X.R., Xaio, H.F., Zhu, Q.R. and Li, P. (2004) Estimation of China's Food Security. China Rural Survey, 25, 14-21.

[9] Wu, W.B, Yang, P., Tang, H.J., Zhou, Q., Chen, Z.X. and Shibasaki, R. (2010) A New Method of Food Safety Assessment. Chinese Journal of Agricultural Resources and Regional Planning, 31, 16-21.

[10] Ma, J.J., Zhang, X.S. and Gui, H.B. (2001) A Study on Assessment Indexes for the Alert System of Food Security. Management World, 17, 154-162.

[11] Liu, X.M. (2004) A Discussion on Systematic Evaluation Indicators for Food Security. Finance \&Trade Economics, 25, 56-61.

[12] NBS (2005) Researching Group of Rural Survey Organization of the Research of System of Indicators to Evaluate Food Supply Security of China. Statistical Research, 22, 3-9.

[13] Fan, D.J. (2013) On the Sustainable Effect of Outflow of Rural Labor Force on Grain Production-An Analysis Based on Provincial Panel Data in Different Areas. Modern Finance and Economics-Journal of Tianjin University of Finance and Economics, 33, 57-69.

[14] Liu, J.H., Li, L.J. and Wang, Z.M. (2004) Study on Food Security Index of China. Journal of Agricultural Science and Technology, 5, 10-16.

[15] Huang, J.K. and Hu, R.F. (2000) Government-Major Funding Source of Agricultural S\&T. Forum on Science and Technology in China, 20, 59-62.

[16] Hu, J. (2000) China's Grains Security: The Nature of Public Goods and Long Term Policy Focus. China Rural Survey, 21, 24-30.

[17] Du, Y.N. (2013) China's Food Security Problem under the National Industrialization Urbanization and Agricultural Modernization. Doctor Thesis, University of Science and Technology of China, Hefei.

[18] Fu, Y.H., Wang, Z.X. (2011) An Evaluation of Quality of Utilizing FDI in High-Technology Industry. Finance \& Trade Economics, 32, 74-80.

[19] Kaiser, H.F. (1974) An Index of Factorial Simplicity. Psychometrika, 39, 31-36. http://dx.doi.org/10.1007/BF02291575 